\title{
The Study of Dielectric Properties and Conductivity Relaxation of Ion Conducting Chitosan:NaTf Based Solid Electrolyte
}

\author{
Shujahadeen B. Aziz ${ }^{1,2, *}$ Soran M. Mamand ${ }^{1}$ \\ ${ }^{1}$ Prof. Hameeds Advanced Polymeric Materials Research Lab., Department of Physics, College of \\ Science, University of Sulaimani, Qlyasan Street, Sulaimani, Kurdistan Regional Government-Iraq \\ ${ }^{2}$ Komar Research Center (KRC), Komar University of Science and Technology, Sulaimani, 46001, \\ Kurdistan Regional Government, Iraq \\ *E-mail: shujaadeen78@yahoo.com, shujahadeenaziz@gmail.com
}

doi: $10.20964 / 2018.11 .05$

Received: 6 June 2018/ Accepted: 12 August 2018 / Published:1 October 2018

\begin{abstract}
The development of ion-conducting chitosan based solid polymer electrolyte has been a subject of great concern due to their large-scale applications. This work shows a study of dielectric properties and conductivity relaxations of chitosan (CS) based solid polymer electrolyte sample. A fixed amount of Sodium trifluoromethanesulfonate $\left(\mathrm{NaCF}_{3} \mathrm{SO}_{3}\right)$ was added to a $\mathrm{CS}$ solution for the fabrication of chitosan- $\mathrm{NaCF}_{3} \mathrm{SO}_{3}$ (CS:NaTf) electrolyte sample. . On the basis of both complex permittivity and complex modulus formalism, the dielectric and conductivity relaxations of the sample were analyzed through impedance data measurements. High values of dielectric constant and dielectric loss were recorded at low frequencies. The dielectric constant and dielectric loss increased with increasing temperature, indicating an increase in conductivity. From the study of frequency dependency of loss tangent, broaden peaks were observed, showing that more than one relaxation process is present. From the real part of electric modulus, the material is featured to be highly capacitive. From the asymmetrical peak shape of the imaginary part of electric modulus, the non-Debye type relaxation is predicted. The main observation shows that the dielectric constant and dielectric loss drop above 388 $\mathrm{K}$. Moreover, the study of surface morphology of the sample exhibited that there are remarkable changes before and after the heat treatment. Lastly, the temperature dependence of peak frequency corresponding to $\tan \delta_{\max }$ and conductivity relaxation time $\left(\tau_{\sigma}\right)$ is found to obey the Arrhenius relationship, which suggests the viscoelastic relaxation for ion transport phenomena.
\end{abstract}

Keywords:chitosan solid electrolyte, dielectric properties, scanning electron microscopy, conductivity relaxation

$\underline{\text { FULL TEXT }}$ 
(C) 2018 The Authors. Published by ESG (www.electrochemsci.org). This article is an open access article distributed under the terms and conditions of the Creative Commons Attribution license (http://creativecommons.org/licenses/by/4.0/). 